\title{
Perspectiva foucaultiana dos discursos em uma aula de Matemática: densidade demográfica
}

\author{
Foucaultian's perspective of the discourse in a math class: demographic \\ density
}

Cymone Martins Cotrim Teixeira

Tânia Cristina Rocha Silva Gusmão

Resumo: Este artigo tem como objetivo apresentar elementos em uma perspectiva foucaultiana dos discursos na análise de um fragmento de aula de Matemática cuja questão trazida é sobre Densidade Demográfica. Tomaremos algumas ferramentas de análise que serão visitadas com maior ou menor frequência no decorrer do texto: o discurso, o saber, o poder e a resistência. Tencionou-se buscar o lugar de fala dos sujeitos, o saber construído no processo de aprendizagem matemática, o exercício do poder e identificar elementos de resistência no contexto da sala de aula, onde a atividade foi aplicada. Conclui-se que a instituição escolar, lugar de produção e circulação dos discursos, evidencia um modo de pensar exercendo um poder que inclui, exclui e controla os saberes.

Palavras-chave: Discursos. Saber matemático. Poder. Resistência.

Abstract: This article aims to present elements from a foucaultian perspective from the discourses in the analysis of a fragment of a Mathematics class whose question is about Demographic density. We will take some analysis tools that will be visited more or less frequently throughout the text: speech, knowledge, power and resistance. It was intended to seek the place of speech of the subjects, the knowledge built in the process of mathematical learning, the exercise of power and identify elements of resistance in the context of the classroom, where the activity was applied. It is concluded that school institution, place of production and circulation of discourses, evidences a way of thinking exerting a power that includes, excludes and controls knowledge.

Keywords: Speeches. Mathematical knowledge. Power. Resistance.

Cymone Martins Cotrim Teixeira Mestre em Ensino pela Universidade Estadual do Sudoeste da Bahia (UESB) Professora de Atendimento Especializado (Braille) no Centro Estadual de Educação Especial de Caetité. Bahia, Brasil.

(iD) orcid.org/0000-0002-2211-9171 $\triangle$ cymonecotrim@gmail.com

Tânia Cristina Rocha Silva Gusmão Doutora em Didática da Matemática pela Universidade de Santiago de Compostela (USC), Espanha. Professora do Programa de Pós-Graduação em Ensino da Universidade Estadual do Sudoeste da Bahia (UESB), campus Vitória da Conquista. Bahia, Brasil. iD orcid.org/0000-0001-6253-0435 $\bowtie$ professorataniagusmao@gmail.com Recebido em 12/08/2019 Aceito em 18/09/2019 Publicado em 10/02/2020

\section{Introdução}

Neste artigo apontamos elementos do discurso na perspectiva foucaultiana, tomando por base um fragmento de aula de Matemática cuja questão trazida é sobre Densidade Demográfica. Este tema foi provocado durante uma aula da disciplina Teorias da Aprendizagem, no Mestrado Acadêmico em Ensino da Universidade Estadual do Sudoeste da Bahia (PPGEn/UESB). 0 fragmento de aula, apresentado para ser analisado a partir de diferentes teorias, logo nos direcionou para as postulações e teorizações de Michel Foucault, referencial que aponta caminhos para pensar o discurso dos atores, seu lugar de fala e suas implicações no contexto apresentado. 
Desse modo, o percurso metodológico respaldado em Michel Foucault tomará a análise arqueológica como princípio para "analisar o grau e a forma de permeabilidade de um discurso: apresenta o princípio de sua articulação com uma cadeia de acontecimentos sucessivos; define os operadores pelos quais os acontecimentos se transcrevem nos enunciados" (FOUCAULT, 2017, p. 204).

Neste entendimento, "no discurso [...] buscaremos antes um campo de regularidade para diversas posições de subjetividade" (FOUCAULT, 2017, p. 66), o filósofo não se detém ao discurso já pronto, mas as condições em que são produzidos (GREGOLIN, 2006), o que implica nomear alguns dispositivos de análise que serão visitados com maior ou menor frequência no decorrer do texto: o discurso, o saber, o poder e a resistência.

O campo do saber matemático perfaz o caminho da pesquisa e do ensino que integram diferentes grupos responsáveis pela construção da verdade matemática. Para Foucault (1995), as "sociedades de discursos", produzem discursos que circulam de acordo com regras préestabelecidas e estes tomam forma de verdade. Assim, "[...] cada sociedade tem seu regime de verdade, sua política geral de verdade: isto é, os tipos de discurso que ela acolhe e faz funcionar como verdadeiro". (FOUCAULT, 1995, p. 232).

Daí a importância de identificar os espaços de construção, os sujeitos que fazem circular estes discursos e suas implicações no contexto de aprendizagem escolar. Neste interim, tencionase buscar o lugar de fala dos sujeitos, o saber construído no processo de aprendizagem matemática, o exercício do poder e identificar elementos de resistência no contexto da sala de aula, onde a atividade foi aplicada.

\section{Postulados e teorizações foucaultianas: reconhecendo o arcabouço de análise}

Tomando o sujeito como objeto de estudo, Foucault destaca um conjunto de regras que são próprias da prática discursiva, formando os objetos de que falam os discursos, signos, a produção da verdade em determinado tempo histórico. Neste sentido, "não é preciso remeter 0 discurso à longínqua presença da origem; é preciso tratá-lo no jogo de sua instância" (FOUCAULT, 2017, p. 31).

Do ponto de vista foucaultiano, a análise arqueológica "individualiza e descreve formações discursivas, isto é, deve compará-las, opô-las umas às outras na simultaneidade em que se 
apresentam, distingui-las das que não tem o mesmo calendário, relacioná-las no que podem ter de específico com as práticas não discursivas" (FOUCAULT, 2017, p. 192).

Desse modo, o discurso, o saber, o poder e a resistência serão as ferramentas que constituirão o processo de análise nessa proposta de fragmento de aula, visto que "o discurso, aparentemente, pode até nem ser nada de por aí além, mas, no entanto, os interditos que 0 atingem, revelam, cedo, de imediato, o seu vínculo ao desejo e ao poder" (FOUCAULT, 2012, p. 2). 0 discurso aqui tomado a partir da compreensão do enunciado "na estreiteza e singularidade de sua situação; de determinar, de fixar seus limites da forma mais justa, de estabelecer suas correlações com outros enunciados a que pode estar ligado" (FOUCAULT, 2012, p. 34).

Desta forma, ao defrontar o discurso matemático, que se apresenta por uma vontade de verdade de constituir-se como um poder coercitivo sobre os demais discursos, analisa-se as condições históricas, sociais, econômicas e políticas que permitiram emergir essas políticas com esse desejo. Neste sentido, as relações de poder é sempre uma ação de alguns sobre a ação de outros (FOUCAULT, 1995). Daí a importância de investigar como ele se exerce, quais os mecanismos de sua ação e formas de subjetivação, uma vez que na análise do poder não se tem um poder que destrói o indivíduo, mas um poder que subjetiva um indivíduo (MACHADO, 2015).

Ainda na fase arqueológica, o saber é compreendido a partir das condições que possibilitaram seu surgimento e sua transformação, Foucault "pretende fazer uma investigação mais profunda do que a empreendida pela ciência" (VEIGA-NETO, 2017, p. 48). "Ela se ocupa do saber em sua relação com as figuras epistemológicas e as ciências, pode, do mesmo modo, interrogar o saber em uma direção diferente e descrevê-lo em um outro feixe de relações" (FOUCAULT, 2017, p. 236). Faz referência aos saberes que se manifestam por meio de discursos científicos tidos como verdadeiros, positivos, por isso, tomados em sua positividade.

O poder não se encontra fora do discurso, está em todo lugar, tudo é controlado. Esse controle e poder produzem a subjetividade, "o que é notável no poder disciplinar é que ele "atua" ao nível do corpo e dos saberes" (VEIGA-NETO, 2017, p. 48) e, neste sentido, a ferramenta da resistência é empregada por Foucault para identificar uma forma pela qual o indivíduo consegue "de maneira voluntária ou fortuita, "escapar" dos dispositivos de identificação, de classificação e de normatização do discurso" (REVEL, 2005, p. 74).

O poder disciplinar é o tema de aproximação entre Foucault e a educação. Apesar do filósofo não ter se dedicado ao tema, associou a função da escola e da educação escolar ao uso 
da tecnologia da disciplina como modo de disciplinamento dos corpos, distribuição e apropriação dos discursos. Para ele,

[...] a educação, embora seja, de direito, o instrumento graças ao qual todo indivíduo, em uma sociedade como a nossa, pode ter acesso a qualquer tipo de discurso, segue, em sua distribuição, no que permite e no que impede, as linhas que estão marcadas pela distância, pelas oposições e lutas sociais. Todo sistema de educação é uma maneira política de manter ou de modificar a apropriação dos discursos, com os saberes e os poderes que eles trazem consigo (FOUCAULT, 2012, p. 41).

Diante do exposto, tomamos tais ferramentas de análise para estabelecer relações entre os discursos, investigando o dito dentro da teia de formações discursivas encontradas, entrelaçadas, como afirma Foucault (2006),

o tipo de análise que eu pratico não se ocupa do problema do sujeito falante, mas examina as diferentes maneiras pelas quais o discurso cumpre uma função dentro de um sistema estratégico onde o poder está implicado e pelo qual o poder funciona. ( $p$. 465)

Muito embora Foucault não tenha se dedicado diretamente à educação, seus estudos possibilitam compreender os discursos e os objetos do seu campo de saber. Neste sentido, VeigaNeto (2017), ao analisar os postulados foucaultianos na perspectiva da educação escolar, vislumbra que "foi com base em Foucault que se pôde compreender a escola como uma eficiente dobradiça capaz de articular os poderes que aí circulam com os saberes que a enformam e aí ensinam, sejam eles pedagógicos ou não" (p. 15).

Desse modo, tomaremos a unidade elementar do discurso, o enunciado, visando enxergar nos enunciados do fragmento de aula, uma articulação dialética entre o que é singular e o que se repete: o gesto; a memória, uma materialidade; uma unidade, que está aberta à repetição e se liga ao passado e ao futuro, como ressaltou Gregolin (2006). Neste sentido, "a materialidade é constitutiva do enunciado - ele precisa ter uma substância, um suporte, um lugar, uma data, isto é, está determinado por um "regime de materialidade" (GREGOLIN, 2006, p. 93).

Os enunciados apoiam-se numa mesma formação discursiva. Esta, "coloca o princípio da articulação entre uma série de acontecimentos, transformações, mutações, processos" (FOUCAULT, 2012, p. 83). Desse modo, na análise empreendida, não se busca desvendar "a universalidade de um sentido; ela mostra à luz do dia o jogo da rarefação imposta, com um poder fundamental de afirmação" (FOUCAULT, 2012, p. 70). Entendendo que em Foucault (2017), um enunciado é sempre um acontecimento que nem a língua nem o sentido podem esgotar 
Quadro 2: Fragmento de aula de Matemática

1. A: Este é um problema sobre densidade, pois as informações são sobre densidade.

2. P: Ok (disseram para Alícia que ela precisa explicar melhor). Nós sabemos que você sabe muito, mas...

3. A: Em B1 a densidade é menor que em B2. É isso.

4. P: Emílio disse: não.

5. E: Eu não entendo! Algo está faltando.

6. P: [perguntaram a Emílio]. Como você resolveu?

7. E: É claro que B2 tem mais pessoas e menos espaço. Fui ali. Os apartamentos são muito pequenos.

8. P: O que você fala é verdade, mas, como responde a segunda pergunta?

9. E: Para mim, a segunda pergunta não está boa.

10. P: Por quê?

11. E: Eu não mudaria sozinho, iria com toda a minha família.

12.P: A que você está se referindo?

13. E: Eu mudaria a segunda pergunta.

14.P: Não comece de novo, Emílio! Você sabe que os problemas são desse jeito.

15. M: Não me importa trocar a pergunta, mas se trocamos, nós não exercitamos a Matemática que o professor quer que exercitemos. Pode fazer isso por tentativa e erro, é só começar fazendo 50.000 pessoas.

16. A: Isso não é Matemática!

17. E: Por que isso não é Matemática?

18. P: Melhor continuarmos. Alícia, qual é a sua opinião?

19. A: Eu já disse. Este é um problema de densidade.

20. P: Você sabe o que está dizendo, porém está cansada...

21. A: Vou ao quadro?

22. P: [O professor move a cabeça em consentimento]

23. A: [No quadro]

$$
\begin{aligned}
& \frac{65075}{7} \rightarrow \frac{65072}{7}=9296 \mathrm{~h} / \mathrm{km}^{2} \text { en B1 } \\
& \frac{190030}{5}=38006 \mathrm{~h} / \mathrm{km}^{2} \text { en B2; } 9296<38006
\end{aligned}
$$

24.P: Certo, nós necessitamos comparar os dois bairros. Estes números não significam nada se nós não os compararmos.

25. A: Este número [9296] é...

26. E: Nós colocamos algumas pessoas aqui e outras lá.

27. A: Deixe-me terminar! 9296 é menor 38006. Isso significa que em B1 vive-se mais 
espaçosamente.

28. P: Certo.

29. A: Agora vejamos a equação. [No quadro]

$$
\begin{aligned}
& \frac{190030-x}{5}=\frac{65072+x}{7} ; 38006-\frac{x}{5}=9296+\frac{x}{7} ; 38006-9296=\frac{x}{5}+\frac{x}{7} ; \\
& 28710=\frac{12 x}{35} ; x=\frac{28710-35}{12} ; x=83737,5 \rightarrow 83737 \text { personas } \\
& \ldots . . . . .
\end{aligned}
$$

30. P: Alícia, você tem que explicar melhor o que fez e o porquê.

31. E: Eu não entendo o porquê de trocar 65075 por 65072.

32. P: Alícia? Por que você substituiu esse número?

33. A: [Retorna ao seu lugar]. Eu já expliquei minha proposta, agora eles que expliquem.

34. M: Eu não acredito que necessitamos fazer uma equação. Por que não tentamos com diferentes números? Não necessitamos serem exatos aqui, não é?

35. P: Vejamos novamente a proposta de Alícia. [Para Emílio]. Alguém quer mudar a segunda pergunta

36. E: Todos nós conhecemos esses bairros, não é estranho o que ela está fazendo? Por que temos que usar densidades e equações?

37. M: [Ao professor] Por que ela moveu três pessoas daqui [65072]?

38. P: Mateus, vamos nos concentrar, esqueça as pessoas e pense somente na fração. $O$ número 65075 é múltiplo de 7 ?

39. M: Não.

40. P: Essa é a questão! 65072 é um múltiplo de 7 e 65075 não é. Agora podemos fazer a divisão exata.

41. M: Mas isso não se trata de números, e sim de pessoas!

42. E: Na última operação ela não olha os múltiplos, verdade?

43. A: Isso não é importante.

44. P: Você viu como ela resolveu a equação?

45. M: Sim.

46. P: Isso é importante.

47. M: Podemos dar uma resposta aproximada?

48. A: Por favor, isso não é importante.

49. M: Copiamos a equação?

50. P: Primeiro vamos organizar nossas ideias. Além de calcularmos as densidades, necessitamos que elas sejam iguais. Esta é uma proposta. E vocês [apontando] para o outro grupo? Qual é a solução que encontraram?

Fonte: Font, Planas e Godino (2010, p. 93-94)

Os critérios estabelecidos para a seleção dos enunciados estão diretamente relacionados 
aos postulados que propomos analisar: Sujeito de fala - Professor; Espaço - Escola; Sujeitos do discurso/saber/poder e resistência - alunos.

Esses sujeitos nos permitem, em seus discursos, acolher cada momento do discurso, sua irrupção, sua pontualidade quando aparece, suas dispersões. O que permite ser repetido, apagado, esquecido e transformado, não sendo necessário buscar sua origem, mas tratá-lo no jogo das relações onde este está inserido.

\section{Os discursos e os objetos que constituem o seu campo de saber}

Para Foucault (2017, p. 63), o lugar de fala são o que "as posições do sujeito se definem igualmente pela situação que lhe é possível ocupar em relação aos diversos domínios ou grupos de objetos: ele é o sujeito que questiona".

Quadro 3: Espaço - (Escola) $)^{1}$

A escola está localizada em uma região onde grande parte da população pertence à classe média de trabalhadores e seus alunos são de diferentes culturas, religiões e capacidades cognitivas. De modo geral, pode-se dizer que esses alunos apresentam um nível socioeconômico similar (renda baixa).

O excerto acima nos leva a inferir o espaço de fala dos sujeitos, enquanto lugar de aprendizagem formal, constituindo o lócus de pertencimento. A este respeito, Foucault (2012) posiciona o sistema de ensino como a "ritualização da fala, senão uma qualificação e uma fixação de papéis dos sujeitos falantes" (2012, p. 12). Ao descrever a classe econômica, e os alunos como pertencentes a diferentes religiões, culturas e nível cognitivo, o professor faz uma leitura pessoal das percepções que recolhe do ambiente ao longo dos seus anos de experiência que será relatado adiante. $\mathrm{O}$ alerta do filósofo permite-nos recorrer à sua fala quando explicita um dos princípios de especificidade do discurso, "não dissolver o discurso num jogo de significações prévias; não imaginar que o mundo nos mostra uma face legível que apenas teríamos de decifrar" (FOUCAULT, 2012, p. 14). Neste caso, o cenário nos desloca para a posição do sujeito que fala, e o lugar que ocupa na rede de informações, assim "as posições do sujeito se definem igualmente pela situação que lhe é possível ocupar em relação aos diversos domínios ou grupos de objetos" (FOUCAULT, 2017, p. 63).

Levando em consideração que não estando o discurso pronto, Foucault estuda, sim, "as

\footnotetext{
${ }^{1}$ Tal episódio se encontra no artigo de Font, Planas e Godino (2010), anexo 3.
} 
suas condições de produção" (GREGOLIN, 2006, p. 70). O Quadro 4 nos remete ao discurso construído pelo professor ao longo de sua experiência conduzindo suas percepções que no método arqueológico define-se "na busca de elementos que possam ser articulados entre si e que fornecem um panorama coerente das condições de produções de produção de um saber em certa época" (GREGOLIN, 2006, p. 71).

Quadro 4: Sujeito (Professor)

Sobre o professor regente, este possui muitos anos de experiência no ensino e há três anos trabalhando nessa escola.

O lugar de fala dos sujeitos indica que, "ninguém entrará na ordem dos discursos se não satisfazer certas exigências, ou se não estiver, à partida, qualificado para o fazer" (FOUCAULT, 2012, p. 10). É preciso conhecer o lugar institucional de onde o professor fala, onde está sua origem legítima. Neste sentido, sua posição se define pela situação que lhe é possível ocupar.

Como o enunciado do excerto abaixo (Quadro 5), o saber matemático posto anteriormente como verdade, foi considerado apreendido, visto que "esta vontade de verdade, por fim, apoiandose numa base e numa distribuição institucionais, tende a exercer sobre os outros discursos contínuo a falar da nossa sociedade - uma espécie de pressão e um certo poder de constrangimento" (FOUCAULT, 2012, p. 4-5).

Quadro 5: Sujeito (Professor)

$O$ docente considerou que eles tinham pré-requisitos para responder dados que no ano anterior haviam trabalhado (a compreensão dos assuntos proporcionalidade e equações).

Compreende-se os discursos dos sujeitos e seus movimentos de resistência e poder no decorrer dos diálogos enunciativos extraídos do fragmento de aula, estabelecendo a relação entre os enunciados e como estes se inscrevem e compreendem a que poder atendem, ativam e colocam em circulação (VEIGA-NETO, 2017).

Quadro 6: Sujeito (Alunos)

1. A: Este é um problema de densidade, pois as informações são sobre densidade.

2. P: Ok. (Disseram para Alicia que ela precisa explicar melhor). Nós sabemos que você sabe muito, mas...

O excerto acima, Quadro 6, realça o poder gerado pelo saber na fala da aluna Alicia, que conforme lemos, é interpelada pelo colega a explicar melhor uma vez que sabe $\mathrm{O}$ assunto. $\mathrm{Na}$ 
articulação entre poder e saber, "os saberes se engendram e se organizam para "atender" a uma vontade de poder" (FOUCAULT, 2012, p. 10). No decorrer do diálogo, Alicia se sobressai na resolução da questão apresentando soluções possíveis, dentro do que seria esperado pelo saber matemático, atendendo à produção e circulação de discursos sobre o ensino e a aprendizagem de Matemática. Os discursos tornam possíveis que elementos como resistência, poder e saber sejam analisados como processos de contribuição para o posicionamento dos sujeitos de fala.

No excerto abaixo, Quadro 7, é possível observar dois elementos distintos, o lugar de fala do aluno, que já esteve no local onde estão os apartamentos e entrou em um dos imóveis, conhece, portanto, sua estrutura e analisa a partir da sua vivência. Para Foucault (2017), "é preciso somar as posições que o sujeito pode ocupar na rede de informações" (p. 63).

Quadro 7: Sujeito (Alunos)

7. E: É claro que B2 tem mais pessoas e menos espaço. Eu fui ali. Os apartamentos são muito pequenos.

9. E: Pra mim, a segunda pergunta não está boa.

11. E: Eu não mudaria sozinho, iria com toda a minha família.

13. E: Eu mudaria a segunda pergunta.

Outro elemento passível de reconhecimento no Quadro 7 é a resistência do aluno $(E)$, sua intervenção pode ser considerada uma forma de resistência ao poder sendo também resistência às formas de produção e circulação dos saberes que, no caso das escolas, institucionalmente 0 sustenta. Uma forma de resistir ao enquadramento do saber matemático escolar em que cada sujeito precisa ser transcrito em representação do indivíduo por um número. Para este aluno, os sujeitos não se deslocam entre bairros como números, mas com e como famílias: "Eu não mudaria sozinho, iria com toda a minha família".

Para Foucault, a resistência não antecede ao poder que ela enfrenta, sendo a ele coextensiva e contemporânea. "Para resistir", afirma o autor, "é preciso que a resistência seja como o poder", "tão inventiva, tão móvel, tão produtiva quanto ele", e "que, como ele, venha de 'baixo' e se distribua estrategicamente" (FOUCAULT, 2015, p. 360).

A resistência se dá, necessariamente, onde há poder, porque ela é inseparável das relações de poder, assim, tanto a resistência funda as relações de poder, quanto ela é, às vezes, o resultado dessas relações; na medida em que as relações de poder estão em todo lugar, a resistência é a possibilidade de criar espaços de lutas e agenciar possibilidades de transformação em toda parte. (REVEL, 2005, p. 74). 
Os excertos a seguir, Quadros 8, 9 e 10, revelam dentro das relações sociais o poder disciplinar exercido na relação pedagógica entre educador e educando, numa perspectiva de difusão do discurso do saber formal,

o que é, no fim das contas, um sistema de ensino senão uma ritualização da fala, senão uma qualificação e uma fixação dos papéis dos sujeitos falantes; senão a constituição de um grupo doutrinal, por difuso que seja; senão uma distribuição e uma apropriação do discurso com os seus poderes e os seus saberes" (FOUCAULT, 2012, p. 12).

Essa ritualização legitima o saber construído historicamente. Tratar dos discursos nas relações práticas do cotidiano das instituições é lançar nosso olhar crítico as diferentes formas de sujeição do indivíduo, que se tornam mais visíveis nas estratégias que fazem circular tais discursos construídos e instituídos em sua positividade.

Quadro 8: Sujeito (Alunos)

14. P: Não comece de novo, Emílio! Você sabe que os problemas são desse jeito.

15. M: Não me importa trocar a pergunta, mas se trocarmos, nós não exercitaremos a matemática que o professor quer que exercitemos.

Quadro 9: Sujeito (Professor)

38. P: Mateus, vamos nos concentrar, esqueça as pessoas e pense somente na fração. 0 número 65075 é um múltiplo de sete?

Quadro 10: Sujeito (Professor)

50. P: Primeiro vamos organizar nossas ideias. Além de calcularmos as densidades, necessitamos que elas sejam iguais. Esta é uma proposta. $E$ vocês [apontando para outro grupo]? Qual é a solução que encontraram?

O professor, enquanto detentor do discurso da sala de aula, na maior parte do tempo domina a comunicação pedagógica projetando o saber matemático fortemente classificado. A condução da aula projeta, nos estudantes, formas de romper com a rigidez do discurso disciplinar da Matemática como visto na resistência do aluno E no Quadro 7. Ao mesmo tempo em que o discurso exerce o seu poder persuasivo quando o aluno $\mathrm{M}$ propõe manter a questão para 0 exercício correto da solicitação do professor. Este por sua vez, repele o aluno a concentrar-se na resolução da questão. 
A disciplina, segundo Foucault, encontra terreno fértil em lugares fechados não em campo aberto. A escola reconhecidamente como instituição de regulação social, exerce um papel de destaque no controle e docilização dos corpos,

a escola foi a instituição moderna mais poderosa, ampla, disseminada e minuciosa a proceder a íntima articulação entre o poder e o saber, de modo a fazer dos saberes a correria (ao mesmo tempo) transmissora e legitimadora dos poderes que estão ativos nas sociedades modernas e que instituíram e continuam instituindo o sujeito (VEIGANETO, 2017, p. 114).

Identificamos, portanto no contexto do fragmento de aula sobre densidade demográfica, uma produção discursiva dos sabres por meio de dispositivos de poder e resistências. Entendendo que o poder sempre existe em uma ação, e nunca é monocrático, mas recíproco. Há sempre um agente, um espaço, uma ação e uma reação.

\section{Considerações}

A análise das formações discursivas extraídas do fragmento de aula retratada em Font, Planas e Godino (2010), nos trouxeram elementos que apontam um discurso forte do saber matemático, subsidiado pela instituição escolar que produz e faz circular esses discursos. Apreendemos que o saber institucionalizado distribuído de maneira disciplinar pode interferir positiva ou negativamente na aprendizagem dos sujeitos. Tais interferências se abrem como elemento para novos estudos que pretendam compreender a subjetivação desses sujeitos no contexto escolar.

O exercício de análise pondera o lugar de fala dos sujeitos, sua posição de fala, e 0 discurso empreendido para divulgação e controle, resistência, saber, vontade de verdade. Esses saberes impregnados de poder e resistência para uma compreensão do que foi dito. A análise remonta a instituição escolar como esse lugar de produção e circulação dos discursos que evidenciam um modo de pensar exercendo um poder que inclui, exclui e controla os saberes de outros grupos.

\section{Referências}

FONT, Vicenç; PLANAS, Núria; GODINO, Juan Díaz. Modelo para el análisis didáctico en Educación Matemática. Infancia y Aprendizaje, v. 33, n. 1, p. 89-105, 2010 
FOUCAULT, Michel. A ordem do discurso: aula inaugural no College de France, pronunciada em 2 de dezembro de 1970. Tradução de Laura Fraga de Almeida Sampaio. 22 ed. São Paulo: Edições Loyola, 2012.

FOUCAULT, Michel. Estética: Literatura e Pintura, Música e Cinema. Tradução de Inês Autran Dourado barbosa. 2. ed. Rio de Janeiro: Forense Universitária, 2006.

FOUCAULT, Michel. Microfísica do poder. 2 ed. Organização e Tradução de Roberto Machado. Rio de Janeiro: Paz e Terra, 2015.

FOUCAULT, Michel. O sujeito e o poder. In: DREYFUS, Humbert L.; RABINOW, Paul. (Org). Michel Foucault: uma trajetória filosófica - para além do estruturalismo e da hermenêutica. Tradução de Vera Porto Carrero. Rio de Janeiro: Forense Universitária, 1995, p. 231-249.

FOUCAULT, Michel. Arqueologia do saber. Tradução de Luiz Felipe Baeta Neves. 8. ed. Rio de Janeiro: Forense Universitária, 2017.

GREGOLIN, Maria do Rosário Valencise. Foucault e Pêcheux na análise do discurso: diálogos e duelos. 2. ed. São Paulo: Editora Claraluz, 2006.

MACHADO, Roberto. Introdução: Por uma genealogia do poder. In: FOUCAULT, Michel. Microfísica do poder. 2 ed. Organização e Tradução de Roberto Machado. Rio de Janeiro: Paz e Terra, 2015.

REVEL, Judith. Michel Foucault: conceitos essenciais. Tradução de Carlos Piovezani Filho e Nilton Milanez. São Carlos: Claraluz, 2005.

VEIGA-NETO, Alfredo. Foucault e a Educação. 3. ed. Belo Horizonte: Autêntica, 2017. 